\title{
Diversity of Salmonella spp. serovars isolated from the intestines of water buffalo calves with gastroenteritis
}

Giorgia Borriello ${ }^{1 *}$, Maria G Lucibelli', Michele Pesciaroli², Maria R Carullo', Caterina Graziani², Serena Ammendola ${ }^{3}$, Andrea Battistoni ${ }^{3}$, Danilo Ercolini ${ }^{4}$, Paolo Pasquali ${ }^{2}$ and Giorgio Galiero ${ }^{1}$

\begin{abstract}
Background: Salmonellosis in water buffalo (Bubalus bubalis) calves is a widespread disease characterized by severe gastrointestinal lesions, profuse diarrhea and severe dehydration, occasionally exhibiting a systemic course. Several Salmonella serovars seem to be able to infect water buffalo, but Salmonella isolates collected from this animal species have been poorly characterized. In the present study, the prevalence of Salmonella spp. in water buffalo calves affected by lethal gastroenteritis was assessed, and a polyphasic characterization of isolated strains of $S$. Typhimurium was performed.

Results: The microbiological analysis of the intestinal contents obtained from 248 water buffalo calves affected by lethal gastroenteritis exhibited a significant prevalence of Salmonella spp. (25\%), characterized by different serovars, most frequently Typhimurium (21\%), Muenster (11\%), and Give (11\%). The 13 S. Typhimurium isolates were all associated with enterocolitis characterized by severe damage of the intestine, and only sporadically isolated with another possible causative agent responsible for gastroenteritis, such as Cryptosporidium spp., Rotavirus or Clostridium perfringens. Other Salmonella isolates were mostly isolated from minor intestinal lesions, and often (78\% of cases) isolated with other microorganisms, mainly toxinogenic Escherichia coli (35\%), Cryptosporidium spp. (20\%) and Rotavirus (10\%). The S. Typhimurium strains were characterized by phage typing and further genotyped by polymerase chain reaction (PCR) detection of 24 virulence genes. The isolates exhibited nine different phage types and 10 different genetic profiles. Three monophasic S. Typhimurium (B:4,12:1:-) isolates were also found and characterized, displaying three different phage types and three different virulotypes. The molecular characterization was extended to the $7 \mathrm{~S}$. Muenster and $7 \mathrm{~S}$. Give isolates collected, indicating the existence of different virulotypes also within these serovars. Three representative strains of S. Typhimurium were tested in vivo in a mouse model of mixed infection. The most pathogenic strain was characterized by a high number of virulence factors and the presence of the locus agfA, coding for a thin aggregative fimbria.

Conclusions: These results provide evidence that Salmonella is frequently associated with gastroenteritis in water buffalo calves, particularly S. Typhimurium. Moreover, the variety in the number and distribution of different virulence markers among the collected $S$. Typhimurium strains suggests that within this serovar there are different pathotypes potentially responsible for different clinical syndromes.
\end{abstract}

Keywords: Salmonella, Virulence markers, Genetic characterization, Gastrointestinal ecology

\footnotetext{
* Correspondence: giorgia.borriello@izsmportici.it

${ }^{1}$ Istituto Zooprofilattico Sperimentale del Mezzogiorno, Via Salute, 2, 80055, Portici, Italy

Full list of author information is available at the end of the article
}

\section{Biomed Central}

(c) 2012 Borriello et al.; licensee BioMed Central Ltd. This is an Open Access article distributed under the terms of the Creative Commons Attribution License (http://creativecommons.org/licenses/by/2.0), which permits unrestricted use, distribution, and reproduction in any medium, provided the original work is properly cited. 


\section{Background}

Salmonella spp. found in water buffalo (Bubalus bubalis) herds are a matter of concern since they are responsible for serious economic losses in livestock and are a zoonotic agent responsible for foodborne illness [1]. As for bovine calves, Salmonella-induced diseases in water buffalo calves are characterized by severe gastrointestinal lesions, profuse diarrhea, and severe dehydration [1]. Acute salmonellosis generally induces diarrhea, mucous at first, later becoming bloody and fibrinous, often containing epithelial casts. Ingestion is the main route of infection, although it can also occur through the mucosa of the upper respiratory tract and conjunctiva. The major source of infection in the herd is represented by asymptomatic older animals shedding heavy loads of bacteria through feces. Other sources of infection are contaminated forages and water, as well as rodents, wild winged animals, insects and man $[1,2]$. The disease can also cause sudden death without symptoms. Occasionally, the infection is systemic, affecting joints, lungs and/or the central nervous system (CNS) [1]. Moreover, several Salmonella serovars seem to be able to infect water buffalo, mainly affecting 1-12 week old calves, even though reports on salmonellosis in B. bubalis are scarce $[1,3]$.

Water buffalo calves are more frequently affected by gastroenteritis than bovine calves, with mortality rates as high as $70 \%$ in water buffalo species vs. $50 \%$ in bovine $[1,4]$. This difference might be due to a greater susceptibility of water buffalo to gastroenteric pathogens, although it also may reflect the lack of appropriate management practices for this animal species. Therefore, water buffalo represents a suitable model to study causative agents of gastroenteritis. In water buffalo, S. enterica serovar Typhimurium can induce a variety of clinical syndromes with different anatomopathological lesions $[1,3]$. The severity of the disease can depend on several factors, including host-pathogen interactions, which is highly influenced by the route of infection, the infectious dose, natural or acquired host resistance factors, and the possible presence of other pathogens. Moreover, specific Salmonella virulence factors, frequently located on Salmonella pathogenicity islands (SPIs), prophage regions or virulence plasmids, play a key role in the pathogenesis of the gastroenteritis [5].

The current study investigated the intestinal contents collected from 248 water buffalo calves affected by gastroenteritis with lethal outcome to: (i) evaluate the prevalence of Salmonella spp., and (ii) perform a polyphasic characterization of the collected isolates of $S$. Typhimurium.

\section{Results and discussion}

Salmonella spp. were isolated from $25 \%$ of the intestinal contents collected from 248 water buffalo calves affected by gastroenteritis with lethal outcome. Positive samples were detected in subjects bred in 37 of 58 farms (interherd prevalence, $64 \%)$. The S. enterica serovars most frequently isolated were Typhimurium $(\mathrm{n}=13)$, Muenster $(n=7)$ and Give $(n=7)$. Other recovered serovars were: Derby $(n=5), 4$ Bovismorbificans $(n=4)$, Newport $(n=4)$, monophasic $S$. Typhimurium (B:4,12:i:-; $\mathrm{n}=3$ ), Blockley $(\mathrm{n}=2)$, Meleagridis $(\mathrm{n}=2)$, Umbilo $(\mathrm{n}=2)$, Altona $(\mathrm{n}=1)$, Anatum $(\mathrm{n}=1)$, Bredeney $(\mathrm{n}=1)$, Enterica $(-; \mathrm{i} ; 1,2 ; \mathrm{n}=1)$, Gaminara $(\mathrm{n}=1)$, Haardt $(\mathrm{n}=1)$, Hadar $(\mathrm{n}=1)$, Infantis $(\mathrm{n}=1)$, Isangi $(\mathrm{n}=1)$, Kottbus $(\mathrm{n}=1)$, London $(\mathrm{n}=1)$, Muenchen $(\mathrm{n}=1)$, and S.II:41;z;1,5 $(\mathrm{n}=1)$. Phage-typing of the $S$. Typhimurium and monophasic Typhimurium strains (Table 1) indicated a variable distribution of phage types among strains with nine different phage types of 13 Typhimurium strains, and three different phage types out of three monophasic Typhimurium strains.

This study reports a significant prevalence of Salmonella spp. (25\%) in diarrheic water buffalo calves, that are more relevant than those reported in previous studies (11 and 0.8\%) [3,6]. Moreover, in contrast with bovine species where salmonellosis results primarily associated with serovars Dublin and Typhimurium [5], the extremely variable distribution of the observed serovars confirms the absence of a serovar specifically adapted to water buffalo, as previously suggested [1]. These data provide therefore evidence that Salmonella, particularly $S$. Typhimurium, can be potentially considered an important pathogen for this animal species. The definitive phage type 104 (DT104), which has often been associated with multiple-antibiotic-resistant strains with ascertained zoonotic potential and, in many countries, has increased over the past two decades [5], does not seem to be widely spread in water buffalo. Three monophasic S. Typhimurium (B:4,12:i:-) isolates were also found that are $S$. Typhimurium lacking phase two flagellar antigens that have a rapid emergence and dissemination in food animals, companion animals, and humans. More significantly, the public health risk posed by these emerging monophasic $S$. Typhimurium strains is considered comparable to that of other epidemic $S$. Typhimurium [7].

The diagnostic investigation indicated that nonTyphimurium Salmonella isolates were detected with at least another potential pathogen in $78 \%$ of cases (Figure 1A). In 35\% of cases Salmonella was linked with pathogenic Escherichia coli that were characterized for the presence of virulence factors. Other frequent associations were found with Cryptosporidium spp. (20\%) and Rotavirus (10\%) (Figure 1A). Remarkably, S. Typhimurium was never associated with pathogenic E. coli, while it was isolated sporadically with Clostridium perfringens (strain \#82280), Rotavirus (strain \#107025), and Cryptosporidium spp. (strain \#112) (Figure 1B). The 
Table 1 Virulotypes and phage types of the Salmonella Typhimurium and monophasic S. Typhimurium isolates

\begin{tabular}{|c|c|c|c|c|c|c|c|c|c|c|c|c|c|}
\hline \multirow[t]{2}{*}{ Isolate \# } & \multirow[b]{2}{*}{ gipA } & \multirow[b]{2}{*}{$\operatorname{gtg} B$} & \multirow[b]{2}{*}{$g \circ g B$} & \multirow[b]{2}{*}{ sspH1 } & \multicolumn{5}{|c|}{ Genes $^{a}$} & \multirow[b]{2}{*}{ pefA } & \multirow[b]{2}{*}{ agfA } & \multirow[t]{2}{*}{ Genotype \# } & \multirow[t]{2}{*}{ Phage type } \\
\hline & & & & & sodC1 & gtgE & spvC & safC & $\operatorname{csg} A$ & & & & \\
\hline \multicolumn{14}{|c|}{ S. Typhimurium } \\
\hline 16 & - & + & + & + & + & + & + & + & + & + & - & 1 & DT1 \\
\hline 92 & - & + & + & + & + & + & + & + & + & + & + & 2 & DT104 \\
\hline 112 & - & - & - & + & - & - & - & - & + & - & - & 3 & RDNC \\
\hline 148 & + & + & + & + & + & + & - & + & + & - & - & 4 & DT194 \\
\hline 233 & - & + & + & - & + & + & + & + & + & + & - & 5 & DT104 \\
\hline 279 & - & + & + & - & + & + & + & + & + & + & - & 5 & U302 \\
\hline 107025 & - & + & + & - & + & + & + & + & + & - & + & 6 & RDNC \\
\hline 461 & + & + & + & - & + & + & - & + & - & - & - & 7 & DT208 \\
\hline 10606 & - & + & + & + & - & - & + & + & + & + & + & 10 & U302 \\
\hline 51789 & + & + & + & + & - & + & - & + & + & - & + & 8 & DT110 \\
\hline 55137 & + & + & + & + & - & + & - & + & + & - & + & 8 & DT20 \\
\hline 82280 & + & + & + & + & - & + & + & + & + & - & + & 9 & DT110 \\
\hline 83528 & + & + & + & + & - & + & - & + & + & - & + & 8 & $N T^{b}$ \\
\hline Freq. (\%) & 46 & 92 & 92 & 69 & 54 & 85 & 54 & 92 & 92 & 38 & 54 & & \\
\hline \multicolumn{14}{|c|}{ monophasic S. Typhimurium } \\
\hline 154 & - & + & + & + & + & + & - & - & - & - & + & 11 & DT193 \\
\hline 175 & - & - & - & + & - & - & - & + & - & - & - & 12 & U311 \\
\hline 188 & - & - & - & + & - & - & - & - & + & - & + & 13 & NT \\
\hline
\end{tabular}

presence of more pathogens in the same subject might suggest that, as for other animal species [5], diarrhea in water buffalo calves can be characterized by a multifactorial etiology. Data from necroscopic examinations of tissues indicated that the lesions caused by $S$. Typhimurium were characterized by severe damage of the intestine, ranging from congestive to necrotic-ulcerative enterocolitis. In particular, the strains isolated from animals exhibiting the most severe lesions were \#16, \#92, $\# 233$, and \#83528. Among these strains, the two DT104 strains were also found, thus supporting the pathogenic role of this phage type. The other Salmonella serovars were instead isolated from subjects exhibiting a variety of different lesions, mostly minor lesions confined to the jejunum, and often (78\% of cases) associated with other pathogens. Similarly, the monophasic S. Typhimurium strains were detected either with Rotavirus (strain \#154) or st-positive E. coli (strains \#175 and \#188). These data confirm the pathogenic potential of the serovar Typhimurium for water buffalo calves. On the other hand, the scarcity of observed lesions and the frequent presence of more than one microorganism in the same subject hamper a clear understanding of the potential pathogenic role of the non-Typhimurium Salmonella serovars included in this study.
S. Typhimurium and monophasic $S$. Typhimurium strains were further characterized by the molecular detection of 24 genes coding for virulence factors. The genetic characterization (Table 2) included five loci ( $a v r A, s s a Q$, $m g t C$, siiD, and $s o p B$ ) located on SPI 1-5, respectively [8], eight loci (gipA, gtgB, sopE, sodC1, gtgE, gogB, sspH1, and $s s p H 2)$ of prophage origin [9-13], the gene $s p v C$, located on a virulence plasmid [12], and nine genes (stfE, safC, $\operatorname{csg} A, i p f D, b c f C, s t b D, p e f A, f i m A$, and $a g f A$ ) coding for bacterial fimbriae, involved in surface adhesion and gut colonization [5]. As a positive control for the PCR assay, amplification of the chromosomal gene $i n v A$ was carried out for each strain. All the $S$. Typhimurium and monophasic Typhimurium isolates displayed the presence of avrA, ssaQ, mgtC, siiD, sopB, sspH2, stfE, ipfD, bcfC, stbD, and $\operatorname{fim} A$ genes, and the absence of the $\operatorname{sop} E$ gene. Other loci were variably distributed among the strains, with frequency values ranging from $38-92 \%$ (Table 1). On the basis of the presence or absence of the 24 loci included in the study, the 13 strains of $S$. Typhimurium were subdivided into 10 different genotypes (Table 1); however, the isolates with identical genotype displayed different phage types suggesting the presence of 13 different strains. Interestingly, the three monophasic $S$. Typhimurium strains exhibited three different genotypes (Table 1). 


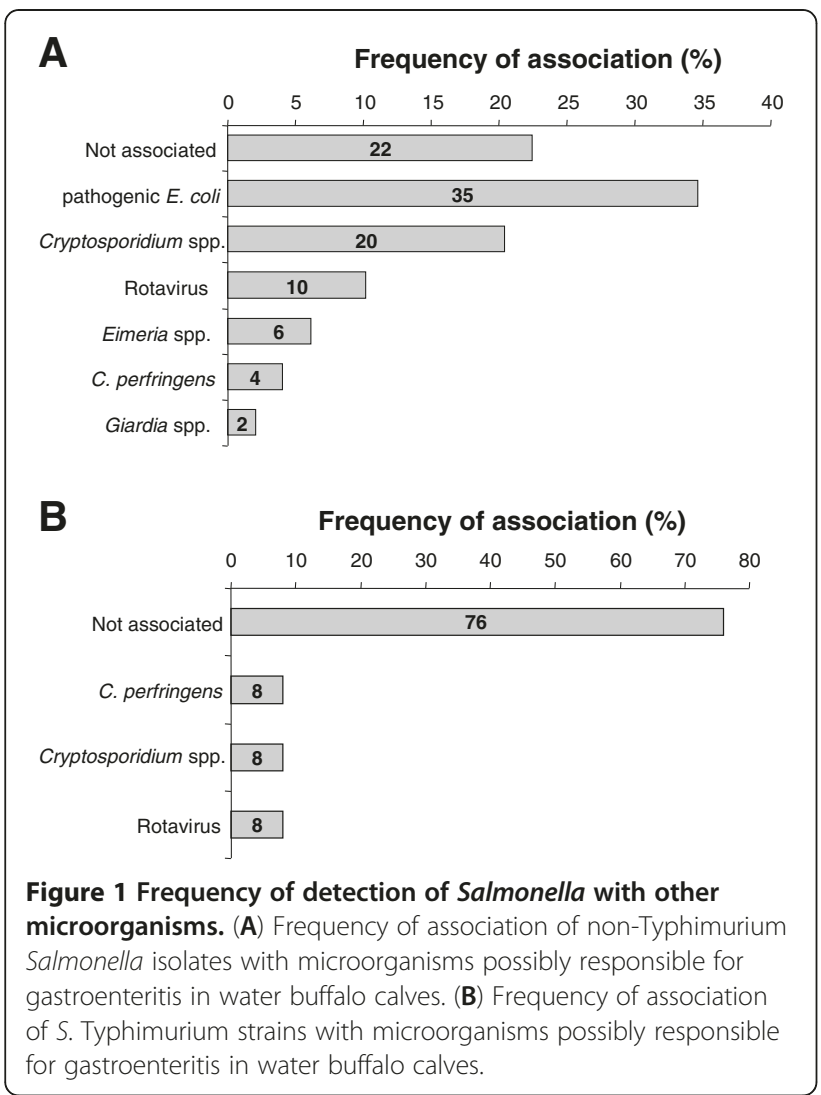

The 24 loci-genetic characterization was also extended to the $S$. Muenster and $S$. Give isolates to investigate their pathogenic potential because of their large presence in water buffalo calves. In addition they have already been reported to cause saepticemic salmonellosis in cattle and calves [14,15]. The molecular results (Table 3) indicated that the loci invA, safC, $b c f C$, fim $A$ and $s s a Q$ were present in all the strains, the genes gipA, $\operatorname{gog} B, \operatorname{sspH} 2$, sodC1, gtgE, spvC, stfE, ipfD and pefA were not found in any of these isolates, while the remaining loci were variably distributed, with frequency values ranging from 14-86\%. In particular, the prophage genes were scarcely present (2 loci in the Muenster serovar, 1 locus in the Give serovar), the plasmidic $s p v C$ locus was absent in all the analyzed isolates, while the fimbrial genes and the SPI 1-5 genetic markers were discretely represented (6 loci for the former genes in both serovars, 5 and 4 loci for the latter genes in the serovar Muenster and Give, respectively). Moreover, the molecular profiles allowed to identify 6 different genotypes out of the 7 $S$. Muenster isolates, and 5 different genotypes out of the $7 \mathrm{~S}$. Give isolates (Table 3).

Our data confirm the high variability of the Typhimurium serovar $[9,10]$, mostly related to virulence factors, and highlight the high discriminating potential of the genotyping technique performed. Our data also suggest that monophasic Typhimurium strains are likely to possess a similarly high degree of genetic variability, particularly linked to virulence markers. Moreover, the presence of virulence markers in the isolated strains of monophasic $S$. Typhimurium, $S$. Muenster and $S$. Give could further support their pathogenic potential. The products of the genes included in the virulotyping assay performed here are known to be important during different stages of infection (Table 2). However, the distribution of these factors among the tested strains highlights the complexity and the variety of potential mechanisms used by Salmonella to induce disease in the host.

The avrA, ssaQ, $m g t C$, siiD, and $\operatorname{sop} B$ genes are genetic markers for the presence of the SPI $1-5$ in all $S$. Typhimurium strains tested, although their presence does not necessarily implicate the presence of the entire SPI. SPIs are clusters of genes on the chromosome, likely to be horizontally acquired, and variably associated with enhanced invasion and intracellular survival within both phagocytic and non-phagocytic cells. In particular, SPI-5 has been largely associated with the ability to produce enteritis [5]. The $S$. Typhimurium strains included in this study all displayed the presence of the investigated SPI markers. Interestingly, these loci appeared widely distributed also among the serovars Muenster and Give. The sopE gene is known to favor the entry of Salmonella into host cells and its presence has been correlated with disease in humans [16] and with the epidemic potential of $S$. Typhimurium strains in cattle [17]. This gene was absent in all the $S$. Typhimurium strains included in the present study, while was present in all the $S$. Muenster strains analyzed.

The pefA (plasmid encoded fimbria), agfA (aggregative fimbria A) and $\operatorname{spvC}$ (Salmonella plasmid of virulence gene C) genes are all located on plasmids [18]. Five $S$. Typhimurium isolates tested in the current study possessed both pefA and $s p v C$, two isolates were positive for only $s p v C$, and three isolates were positive for only agfA (Table 1). These results confirm the presence of more than one virulence plasmid among $S$. Typhimurium strains isolated from diarrheic water buffalo calves, and suggest horizontal exchange of virulence factors. However, the loci $p e f A$ and $s p v C$ were absent in all the monophasic $S$. Typhimurium, $S$. Muenster and $S$. Give strains tested. Prophage genes are known to account for most of the variability of closely-related $S$. Typhimurium strains. Moreover, lysogenic bacteriophages promote changes in the composition of genomic DNA often altering the phenotype of the host $[9,10]$. The prophage virulence genes included in this study exhibited a variable distribution among the isolates tested, thus suggesting synergistic and/or redundant effects of these loci on the pathogenicity of Salmonella, likely contributing to the 
Table 2 Salmonella virulence genes detected by PCR analysis

\begin{tabular}{|c|c|c|c|c|}
\hline Gene & Function & Primer sequence $\left(5^{\prime}-3^{\prime}\right)$ & bp & Reference \\
\hline \multirow[t]{2}{*}{ avrA } & Inhibits the proinflammatory, antiapoptotic NF-kappa B pathway & CCTGTATTGTTGAGCGTCTGG & 422 & [8] \\
\hline & & AGAAGAGCTTCGTTGAATGTCC & & \\
\hline \multirow[t]{2}{*}{$s s a Q$} & Secretion system apparatus protein, component of second T3SS & AATGAGCTGGGTAGGGTGTG & 216 & This study \\
\hline & & ATGCAACGCTAGCTGATGTG & & \\
\hline \multirow[t]{2}{*}{ mgtC } & Intramacrophage survival protein & TGACTATCAATGCTCCAGTGAAT & 677 & [8] \\
\hline & & ATTTACTGGCCGCTATGCTGTTG & & \\
\hline \multirow[t]{2}{*}{ siiD } & HLYD family secretion protein & GTTCATGGTCAGGGCGTTAT & 416 & This study \\
\hline & & GCAAGCAATGCGAGTTCTIT & & \\
\hline \multirow[t]{2}{*}{ sopB } & Translocated effector protein (phosphoinositide phosphatase) via T3SS & TAACGTCAATGGCAAACCAA & 334 & This study \\
\hline & & CCCTCATAAGCACTGGGAAA & & \\
\hline \multirow[t]{2}{*}{ gipA } & Peyer's patch-specific virulence factor & GCAAGCTGTACATGGCAAAG & 212 & [9] \\
\hline & & GGTATCGGTGACGAACAAAT & & \\
\hline \multirow[t]{2}{*}{$g \circ g B$} & Type III-secreted substrate of the infection process & GCTCATCATGTTACCTCTAT & 598 & {$[10]$} \\
\hline & & AGGTTGGTATTTCCCATGCA & & \\
\hline \multirow[t]{2}{*}{ SOpE } & Translocated T3SS effector protein & CGAGTAAAGACCCCGCATAC & 363 & [10] \\
\hline & & GAGTCGGCATAGCACACTCA & & \\
\hline \multirow[t]{2}{*}{$\operatorname{gtg} B$} & Translocated T3SS effector protein & TGCACGGGGAAAACTACTTC & 436 & [9] \\
\hline & & TGATGGGCTGAAACATCAAA & & \\
\hline \multirow[t]{2}{*}{ sspH1 } & Salmonella secreted protein $\mathrm{H} 1$ & TGCAGAAAAAGGGGAATACG & 246 & This study \\
\hline & & GCAGCCTGAAGGTCTGAAAC & & \\
\hline \multirow[t]{2}{*}{ sspH2 } & Salmonella secreted protein $\mathrm{H} 2$ & GCACAACTGGCTGAAGATGA & 203 & This study \\
\hline & & TITCCCAGACGGAACATCTC & & \\
\hline \multirow[t]{2}{*}{ gtgE } & SPI2 type III secreted effector protein & AGGAGGAGTGTAAAGGT & 1114 & [11] \\
\hline & & GTAGAACTGGTTTATGAC & & \\
\hline \multirow[t]{2}{*}{ sodCl } & Periplasmmic Cu, Zn-superoxide dismutases & TATTGTCGCTGGTAGCTG & 468 & [11] \\
\hline & & CAGGTTTATCGGAGTAAT & & \\
\hline \multirow[t]{2}{*}{ spvc } & Spv region promotes rapid growth and survival within the host & ACTCCTTGCACAACCAAATGCGGA & 571 & [12] \\
\hline & & TGTCTTCTGCATTTCGCCACCATCA & & \\
\hline \multirow[t]{2}{*}{ invA } & Enables the bacteria to invade cells & ACAGTGCTCGTTTACGACCTGAAT & 244 & {$[12]$} \\
\hline & & AGACGACTGGTACTGATCGATAAT & & \\
\hline \multirow[t]{2}{*}{ stfE } & Minor fimbrial subunit of the Salmonella Typhi flagella & ATTGGCAATGTGTTGACGA & 185 & This study \\
\hline & & TITGCAGACGGATACCCAAT & & \\
\hline \multirow[t]{2}{*}{ safC } & Pilin outer membrane usher protein & CTCGCTGTCATTGAACTGGA & 158 & This study \\
\hline & & CACCGTGTGATGGTGAAGTC & & \\
\hline \multirow[t]{2}{*}{$\operatorname{csg} A$} & Major fimbrial subunit of thin curled fimbriae & GGATTCCACGTTGAGCATTT & 212 & This study \\
\hline & & CGGAGTITTAGCGTTCCAC & & \\
\hline \multirow[t]{2}{*}{$i p f D$} & The Ipf fimbrial operon mediates adhesion to Peyer's patches & TTCCCTCAATACGCAGGAAG & 183 & This study \\
\hline & & CTCAGGGCTGTGAACTCTCC & & \\
\hline \multirow[t]{2}{*}{ bcfC } & Bovine colonization factor, fimbrial usher & CAGCTTTTCATGACGCGATA & 241 & This study \\
\hline & & CAATGTCTCTGGTTGCGAGA & & \\
\hline \multirow[t]{2}{*}{$s t b D$} & Stability protein involved in a toxin-antitoxin system and in plasmid stability & GGCTGTAATATTCGCCGGTA & 201 & This study \\
\hline & & GCACGCCCTATTCCAGTAAA & & \\
\hline \multirow[t]{2}{*}{ pefA } & Major fimbrial subunit of the plasmid encoded fimbria & ACACGCTGCCAATGAAGTGA & 450 & [18] \\
\hline & & ACTGCGAAAGATGCCACAGA & & \\
\hline
\end{tabular}


Table 2 Salmonella virulence genes detected by PCR analysis (Continued)

\begin{tabular}{|c|c|c|c|c|}
\hline \multirow[t]{2}{*}{$\operatorname{fim} A$} & Type 1 major fimbrial unit & СCTTTCTCCATCGTCCTGAA & 85 & This study \\
\hline & & TGGTGTTATCTGCCTGACCA & & \\
\hline \multirow[t]{2}{*}{$\operatorname{agfA}$} & Aggregative fimbria A & GGATTCCACGTTGAGCATTT & 312 & [18] \\
\hline & & GTTGTTGCCAAAACCAACCT & & \\
\hline
\end{tabular}

phenotypic variability of this pathogen. These loci were mostly present in $S$. Typhimurium and monophasic $S$. Typhimurium rather than in $S$. Muenster and $S$. Give isolates. Fimbrial genes appeared widely distributed among all the serovars tested, particularly in $S$. Typhimurium strains, with frequency values $\geq 92 \%$, except for the plasmid-borne pefA and agfA genes (with frequency values of $38 \%$ and $54 \%$, respectively). These data are consistent with the essential functions of adhesion factors for the attachment and internalization processes that occur during pathogenesis.

To better characterize in vivo virulence, three strains representative of all $S$. Typhimurium isolates were chosen to perform mixed infections in mice. Animal experiments included the two strains exhibiting the highest and the lowest number of virulence factors (strains \#92 and \#112, respectively), and strain \#16, carrying the same virulotype as strain \#92, but that does not harbor the agfA locus (Table 1). In the competition assay, strain \#92 outcompeted both strains \#112 and \#16
(CI $0.004 ; P<0.001$, and CI $0.031 ; P<0.001$, respectively). These results were confirmed in a gastrointestinal mouse model of infection, which better resembles the clinical form of salmonellosis in livestock. Using oral inoculation, in the competition assay, again strain \#92 outcompeted both strains \#112 and \#16 (CI 0.009; $P<0.001$, and CI $0.186 ; P<0.01$, respectively). Our data indicate that among those strains included in the experiment, strain \#92 was the most virulent in mice. These competition assays in mice suggest a key role of the agfA gene coding for a thin aggregative fimbria involved in the colonization of host intestinal epithelial cells by attachment to glycoprotein or glycolipid receptors on epithelial cell surfaces. Indeed, the strain which was more virulent in in vivo experiments was characterized by a high number of virulence factors and by the presence of the agfA locus. Moreover, it was isolated from one of the subjects with necrotic-ulcerative enterocolitis.

The presence of this type of fimbria has been reported in clinical human and animal isolates of Salmonella

Table 3 Virulotypes of the Salmonella Muenster and give isolates

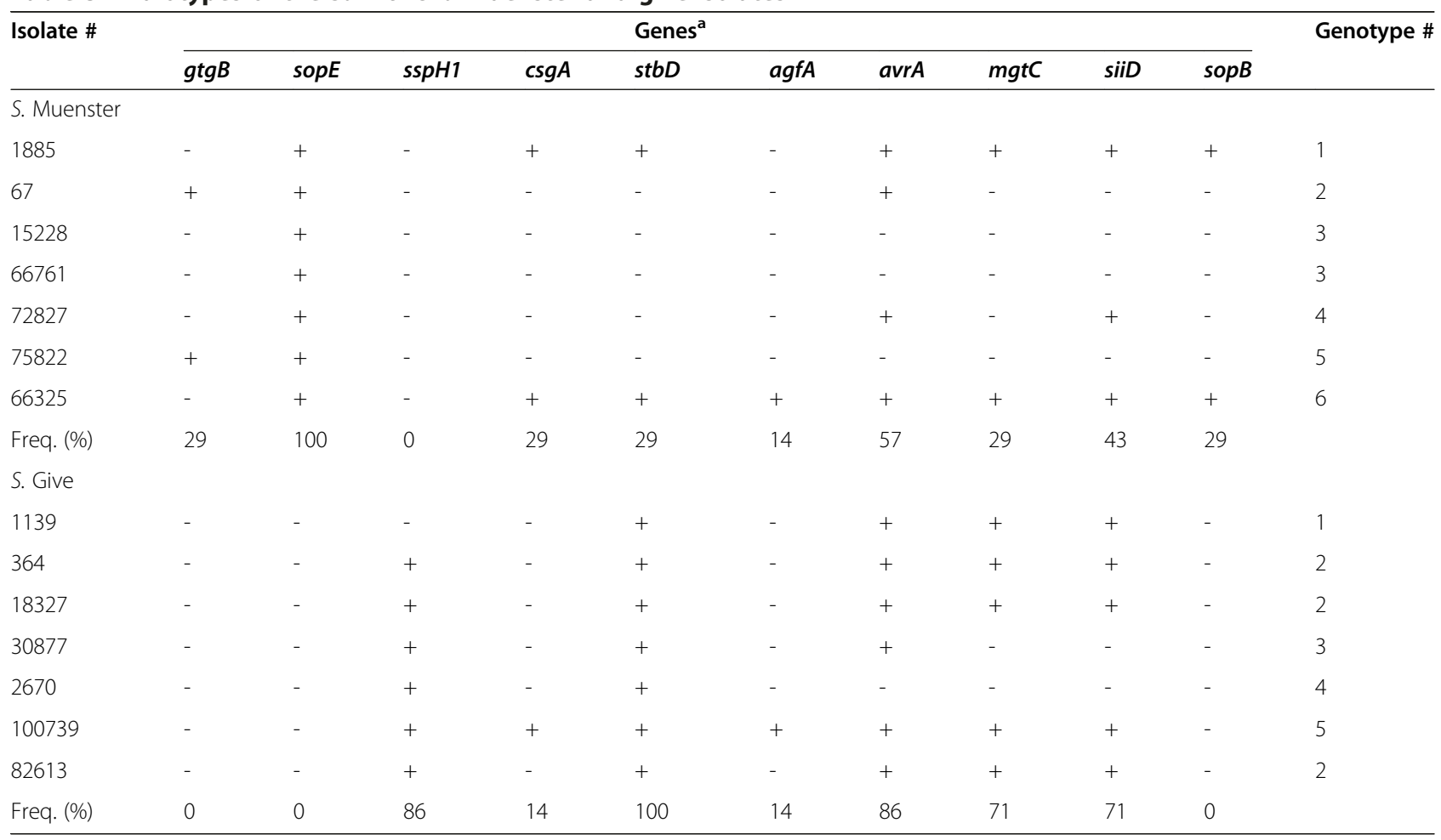

${ }^{a}$ The following loci: invA, safC, bcfC, fimA and ssaQ were present in all the strains; the genes gipA, gogB, sspH2, sodC1, gtgE, spvC, stfE, ipfD and pefA were not found in any of these strains. 
$[19,20]$. The data presented here suggest that agfA might increase bacterial pathogenicity. Nevertheless, we cannot reject the hypothesis that the mouse model chosen for in vivo experiments could have influenced the virulence phenotype of the tested strains originally isolated from water buffalo calves. Therefore, future studies will be necessary to exclude the possibility that the phenotypic differences observed among the tested Salmonellae are dependent on the animal model or on other virulence factors not included in this study. However, in vivo experiments carried out in mouse models represent a good preliminary source of information on the expression of traits associated with pathogenicity of Salmonella in mammalian species.

\section{Conclusions}

This study showed a significant (25\%) prevalence of Salmonella spp. in water buffalo calves affected by gastroenteritis with lethal outcome. However, our results did not indicate the existence of a Salmonella serovar specifically adapted to water buffalo and highlighted that $S$. Typhimurium is the most frequently found serovar. The molecular and phenotypic characterization of the $S$. Typhimurium isolates provided evidence that within this serovar there are different pathotypes potentially responsible for different clinical syndromes, therefore requiring prophylaxis protocols including the use of specific vaccines for the effective control of salmonellosis in water buffalo calves and possible contamination of the food chain.

\section{Methods}

\section{Bacterial strains and diagnostic methods}

This study was carried out in the Campania region, Southern Italy, during 2008-2009, using samples taken from 248 water buffalo calves bred in 58 different farms. The animals were aged between 1-12 weeks old and were all affected by gastroenteritis with lethal outcome. During necropsy, the intestinal lesions were evaluated and the intestinal content of the involved sections was collected and tested for the presence of Salmonella spp. In addition, the presence of E. coli, Eimeria spp., Cryptosporidium spp., Giardia spp., Coronavirus, Rotavirus, and $C$. perfringens were also determined to investigate their association with Salmonella spp.

The isolation of Salmonella spp. was performed according to ISO 6579:2002 [21]. The isolated Salmonella spp. were serotyped according to the Kaufmann-White scheme [22]. Phage-typing of the isolated $S$. Typhimurium strains was performed by the Italian National Reference Centre for Salmonellosis (Istituto Zooprofilattico Sperimentale delle Venezie).

The presence of Rotavirus and Coronavirus was detected by polymerase chain reaction (PCR) amplification [23,24].
Cryptosporidium spp. and Giardia spp. antigens were detected by chromatographic immunoassay (Oxoid, Basingstoke, UK). The presence of Eimeria spp. was examined by flotation technique using saturated saline [25]. E. coli and C. perfringens were isolated according to the protocol reported by Quinn et al. [2]. E. coli hemolytic activity was evaluated by growing colonies on blood agar base, while virulence factors ( $l t$-heat-labile toxin, st-heatstable toxin, stx1-Shiga toxin 1, stx2-Shiga-toxin 2, eaeintimin, $c n f$-cytotoxic necrotizing factor, and $c d t$-cytolethal distending toxin) were detected by molecular assays, as previously reported [26-28].

\section{DNA extraction and molecular assays}

Bacterial DNA was extracted from $1 \mathrm{~mL}$ of overnight cultures using Chelex 100 Resin (BioRad, Hercules, CA) and used as the template for the PCR detection of genes listed in Table 2, as described previously [8-13,18]. The primers used to amplify the genes sspH1, sspH2, ssaQ, sop $B$, siiD, stfE, safC, $\operatorname{csg} A$, ipfD, $b c f C$, stbD, and fimA were designed using the Primer3 software (version 0.4.0; http:// frodo.wi.mit.edu/), and PCR was performed in a final volume of $25 \mu \mathrm{L}$ containing HotStar Taq Master Mix (Qiagen, Valencia, CA) $1 \times, 0.4 \mu \mathrm{M}$ each primer and $1 \mu \mathrm{L}$ of extracted DNA. The thermal profile included an initial denaturation step at $95^{\circ} \mathrm{C}$ for $15 \mathrm{~min}$, followed by 35 cycles at $95^{\circ} \mathrm{C}$ for $30 \mathrm{~s}, 58^{\circ} \mathrm{C}$ for $30 \mathrm{~s}$, and $72^{\circ} \mathrm{C}$ for $1 \mathrm{~min}$, and a final extension step at $72^{\circ} \mathrm{C}$ for $5 \mathrm{~min}$. Amplification products were visualized under ultraviolet (UV) light after electrophoresis on 3\% agarose gels and staining with SYBRsafe (Invitrogen, Carlsbad, CA).

\section{Competition assays in mice}

Groups of five age matched (8-10 weeks old) female $\mathrm{BALB} / \mathrm{c}$ mice used in this study were purchased from Charles River (Calco, Italy). Three strains (S. Typhimurium \#16, S. Typhimurium \#92, S. Typhimurium \#12), representative of the 13 genotypically characterized $S$. Typhimurium isolates, were selected for an in vivo analysis of virulence by using the Competitive Index (CI) resulting from mixed infections [29]. In particular, two strains were selected that exhibited the highest and lowest number of virulence factors (strains \#92 and \#112, respectively), and strain \#16, carrying the same virulotype as strain \#92, but without the locus agfA (Table 1).

Bacteria were grown overnight at $37^{\circ} \mathrm{C}$ in Brain Heart Infusion medium (Oxoid, Basingstoke, UK), washed, and diluted in sterile saline. Cultures were alternatively combined in a mixture of equivalent numbers (1:1 ratio) of two of the three selected strains (input). Mice were inoculated intraperitoneally (IP) with a dose of $2 \times 10^{4}$ bacteria or received $20 \mathrm{mg}$ of streptomycin orally $(200 \mu \mathrm{L}$ of sterile solution or sterile saline) $24 \mathrm{~h}$ prior of being intragastrically administered with $2 \times 10^{7}$ bacteria. The 
number of colony-forming units (CFU) contained in the inocula were confirmed by plating serial dilutions and counting colony growth. At 4 (IP) or 7 (os) days after infection, mice were sacrificed, spleens were aseptically removed, and bacteria were counted by plating serial dilutions (output). The ratio of two strains in the input and in the output was evaluated by picking and transferring 200 colonies on selective plates. Antibiotics used were streptomycin and sulfonamide, for which strain 92 and strains 16 or 112 were naturally resistant. The CI was calculated using the formula: $\mathrm{CI}=$ output (strain A/strain B)/inoculum (strain A/strain B). Statistical differences between outputs and inputs were determined by Student's $t$ test. All animal handling and sampling procedures were performed under the conditions of the local ethics committee meeting the requirements of Italian legislation.

\section{Competing interests}

The authors declare that they have no competing interests.

\section{Authors' contributions}

GB carried out the molecular genetic studies and drafted the manuscript. MGL contributed to the molecular analysis and the isolation and phenotypic characterization of the strains. MP designed and interpreted the results of the in vivo assays. MRC carried out the isolation and phenotypic characterization of the strains. CG participated in the design of the in vivo assays and performed the statistical analysis. SA and AB carried out the in vivo assays and participated in the phenotypic characterization of the strains. DE contributed to the design of the molecular assays, the interpretation of the genotyping results and critical preparation of part of the manuscript. PP participated in the conception, design, and coordination of the study. GG conceived the study, and participated in its design and coordination, and helped to draft the manuscript. All authors read and approved the final manuscript.

\section{Author details}

${ }^{1}$ Istituto Zooprofilattico Sperimentale del Mezzogiorno, Via Salute, 2, 80055 , Portici, Italy. ${ }^{2}$ Istituto Superiore di Sanità, Dipartimento di Sanità Pubblica Veterinaria e Sicurezza Alimentare, Viale Regina Elena, 299, 00161, Rome, Italy. ${ }^{3}$ Università di Roma Tor Vergata, Dipartimento di Biologia, via della Ricerca Scientifica, 1, 00133, Rome, Italy. ${ }^{4}$ Dipartimento di Scienza degli Alimenti, Università degli Studi di Napoli Federico II, Via Università 100, 80055, Portici, Italy.

Received: 8 May 2012 Accepted: 10 October 2012 Published: 25 October 2012

\section{References}

1. Fagiolo A, Roncoroni C, Lai O, Borghese A: Buffalo pathologies. In Buffalo Production and Research. Edited by Borghese A. Rome: FAO Regional Office for Europe Inter-Regional Cooperative Research Network on Buffalo; 2005:249-296

2. Quinn PJ, Markey B, Leonard FC, FitzPatrick ES, Fanning S, Hartigan PJ: Veterinary microbiology and Microbial disease. 2nd edition. West Sussex, UK: Wiley Blackwell; 2011:143-156.

3. Adlakha SC, Sharma SN: Infectious diseases. In World Animal Science C6, Buffalo Productions. Edited by Tulloh NM, Holmes JHG. Parkville: Elsevier; 1992:271-303.

4. Foster DM, Smith GW: Pathophysiology of diarrhea in calves. Vet Clin Food Anim 2009, 25:13-36.

5. Barrow PA, Jones MA, Thomson N: Salmonella. In Pathogenesis of bacterial infections in animals. Edited by Gyles CL, Prescott JF, Songer JG, Thoen CO. Ames: Blackwell Publishing; 2010:231-265.

6. Amrousi SE, Nefie EK, Rehewi ME, Mottilib AA: Studies on enteritis in buffalo calves. Assint J Egypt Vet Med Ass 1971, 31:219-225.
7. EFSA Panel on Biological Hazards (BIOHAZ): Scientific Opinion on monitoring and assessment of the public health risk of "Salmonella Typhimurium-like" strains. EFSA J 2010, 8:1826-1873.

8. Huehn S, La Ragione RM, Anjum M, Saunders M, Woodward MJ, Bunge C, Helmuth R, Hauser E, Guerra B, Beutlich J, Brisabois A, Peters T, Svensson L, Madajczak G, Litrup E, Imre A, Herrera-Leon S, Mevius D, Newell DG, Malorny B: Virulotyping and antimicrobial resistance typing of Salmonella enterica serovars relevant to human health in Europe. Foodborne Pathog Dis 2009, 7:523-535.

9. Mikasova E, Drahovska H, Szemes T, Kuchta T, Karpiskova R, Sasik M, Turna J: Characterization of Salmonella enterica serovar Typhimurium strains of veterinary origin by molecular typing methods. Vet Microbiol 2005, 109:113-120.

10. Drahovska H, Mikasova E, Szemes T, Ficek A, Sasik M, Majtan V, Turna J: Variability in occurrence of multiple prophage genes in Salmonella Typhimurium strains isolated in Slovack Republic. FEMS Microbiol Lett 2007, 270:237-244.

11. Bacciu D, Falchi G, Spazzini A, Bossi L, Marogna G, Sisinnio Leori G, Rubino S, Uzzau S: Transposition of the heat-stable toxin astA gene into a Gifsy2-related prophage of Salmonella enterica serovar abortusovis. J Bacteriol 2004, 186:4568-4574.

12. Chiu CH, Ou JT: Rapid identification of Salmonella serovars in feces by specific detection of virulence genes, invA and spvC, by an enrichment broth culture-multiplex PCR combination assay. J Clin Microbiol 1996, 34:2619-2622.

13. Heithoff DM, Shimp WR, Lau PW, Badie G, Enioutina EY, Daynes RA, Byrne BA, House JK, Mahan MJ: Human Salmonella clinical isolates distinct from those of animal origin. Appl Environ Microbiol 2008, 74:1757-1766.

14. Radke BR, MCFall M, Radostits SM: Salmonella Muenster infection in a dairy herd. Can Vet J 2002, 43:443-453.

15. Higgins R, Désilets A, Cantin M, Messier S, Khakhria R, Ismaïl J, Mulvey MR, Daignault D, Caron H: Outbreak of Salmonella Give in the province of Quebec. Can Vet J 1997, 38:780-781.

16. Hopkins KL, Threlfall EJ: Frequency and polymorphism of sopE in isolates of Salmonella enterica belonging to the ten most prevalent serotypes in England and Wales. J Med Microbiol 2004, 53:539-543.

17. Mirold S, Rabsch W, Rohde M, Stender S, Tschäpe H, Rüssmann H, Igwe E, Hardt WD: Isolation of a temperate bacteriophage encoding the type III effector protein SopE from an epidemic Salmonella typhimurium strain. Proc Natl Acad Sci USA 1999, 96:9845-9850.

18. Smith KP, George J, Cadle KM, Kumar S, Aragon SJ, Hernandez RL, Jones SE, Floyd JL, Varela MF: Elucidation of antimicrobial susceptibility profiles and genotyping of Salmonella enterica isolates from clinical cases of salmonellosis in New Mexico in 2008. World J Microbiol Biotechnol 2010, 26:1025-1031.

19. Doran JL, Collinson SK, Burian J, Sarlós G, Todd EC, Munro CK, Kay CM, Banser PA, Peterkin PI, Kay WW: DNA-based diagnostic tests for Salmonella species targeting agfA, the structural gene for thin, aggregative fimbriae. J Clin Microbiol 1993, 31:2263-2273.

20. Pasmans F, Martel A, Boyen F, Vandekerchove D, Wybo I, Immerseel FV, Heyndrickx M, Collard JM, Ducatelle R, Haesebrouck F: Characterization of Salmonella isolates from captive lizards. Vet Microbiol 2005, 110:285-291.

21. UNI EN ISO 6579: Annex D "Detection of Salmonella spp. in animal feces and in environmental samples from primary production stage". 2002.

22. Grimont PAD, Weill FX: Antigenic formulae of the Salmonella serovars. 9th edition. Paris: WHO Collaborating Centre for Reference and Research on Salmonella; 2007:1-166.

23. Stephensen CB, Casebolt DB, Gangopadhyay NN: Phylogenetic analysis of a highly conserved region of the polymerase gene from 11 coronaviruses and development of a consensus polymerase chain reaction assay. Virus Res 1999, 60:181-189.

24. Logan C, O'Leary JJ, O'Sullivan N: Real-time reverse transcription-PCR for detection of rotavirus and adenovirus as causative agents of acute viral gastroenteritis in children. J Clin Microbiol 2006, 44:3189-3195.

25. Hendrix CM: In Internal parasites In Laboratory procedures for veterinary technicians. 5th edition. Edited by Hendrix CM, Sirois M. St. Louis: Elsevier; 2007:81-229.

26. Toth I, Hérault F, Beutin L, Oswald E: Production of cytolethal distending toxins by pathogenic Escherichia coli strains isolated from human and animal sources: establishment of the existence of a new $c d t$ variant (type IV). J Clin Microbiol 2003, 41:4285-4291. 
27. Vidal M, Kruger E, Durán C, Lagos R, Levine M, Prado V, Toro C, Vidal R: Single multiplex PCR assay to identify simultaneously the six categories of diarrheagenic Escherichia coli associated with enteric infections. J Clin Microbiol 2005, 43:5362-5365.

28. Borriello G, Lucibelli MG, De Carlo E, Auriemma C, Cozza D, Ascione G, Scognamiglio F, lovane G, Galiero G: Characterization of enterotoxigenic $E$. coli (ETEC), Shiga-toxin producing E. coli (STEC) and necrotoxigenic E. coli (NTEC) isolated from diarrhoeic Mediterranean water buffalo calves (Bubalus bubalis). Res Vet Sci 2012, 93:18-22.

29. Beuzón CR, Holden DW: Use of mixed infections with Salmonella strains to study virulence genes and their interactions in vivo. Microbes Infect 2001, 3:1345-1352

doi:10.1186/1746-6148-8-201

Cite this article as: Borriello et al:: Diversity of Salmonella spp. serovars isolated from the intestines of water buffalo calves with gastroenteritis. BMC Veterinary Research 2012 8:201.

\section{Submit your next manuscript to BioMed Central and take full advantage of:}

- Convenient online submission

- Thorough peer review

- No space constraints or color figure charges

- Immediate publication on acceptance

- Inclusion in PubMed, CAS, Scopus and Google Scholar

- Research which is freely available for redistribution 